\title{
Article
}

\section{Reviewing the family unit as a stakeholder in talent development: Is it undervalued?}

Taylor, Robin David and Collins, David John

Available at http://clok.uclan.ac.uk/12233/

Taylor, Robin David ORCID: 0000-0001-9530-8355 and Collins, David John ORCID: 0000-0002-7601-0454 (2015) Reviewing the family unit as a stakeholder in talent development: Is it undervalued? Quest, 67 (3). pp. 330 343. ISSN 0033-6297

It is advisable to refer to the publisher's version if you intend to cite from the work. http://dx.doi.org/10.1080/00336297.2015.1050747

For more information about UCLan's research in this area go to http://www.uclan.ac.uk/researchgroups/ and search for < name of research Group>.

For information about Research generally at UCLan please go to http://www.uclan.ac.uk/research/

All outputs in CLoK are protected by Intellectual Property Rights law, including Copyright law. Copyright, IPR and Moral Rights for the works on this site are retained by the individual authors and/or other copyright owners. Terms and conditions for use of this material are defined in the policies page.

\section{CLoK}

Central Lancashire online Knowledge www.clok.uclan.ac.uk

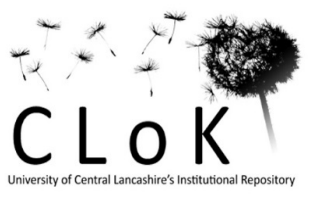


Running head: THE VALUE OF THE FAMILY IN TALENT DEVELOPMENT

This is an Accepted Manuscript of an article published by Taylor \& Francis in Quest in July 2015, available online: http://dx.doi.org/10.1080/00336297.2015.1050747

\section{PLEASE REFER TO THE PUBLISHED VERSION FOR CITING PURPOSES}

Reviewing the family unit as a stakeholder in Talent Development: Is it undervalued?

Robin David Taylor* and Dave Collins

Institute of Coaching and Performance, University of Central Lancashire, Preston, United Kingdom

*Correspondence concerning this article should be addressed to Robin Taylor, Institute of Coaching and Performance, University of Central Lancashire, Preston, PR1 2HE. Email: RDTaylor2@uclan.ac.uk 


\begin{abstract}
As elite youth sport becomes more organized and professionalized, the role of the family is increasingly acknowledged as significant to the development of young talent. High profile examples across a range of professional sports, both positive and negative, have drawn attention towards this important stakeholder. Accordingly, in this review we first examine the key issues in relation to family involvement in Talent Development, with relation to what is perceived as good and bad practice on behalf of the family. We next consider the key theoretical underpinning, Family Systems Theory, and how it may be integrated within elite youth sport. Finally, we conclude with a summary of where the current literature leaves us, and where we can progress from here. We suggest two possible inputs that could benefit the effectiveness of family involvement, with a focus on the family holistically, and a second on the role different family members can play.
\end{abstract}

Keywords: Family Systems Theory, parental involvement, siblings, significant others 


\section{Reviewing the family unit as a stakeholder in Talent Development: Is it undervalued?}

The importance of family support systems within the context of elite performance cannot be underestimated, with family playing a crucial role in an athlete's continued development to the top of their chosen sport (Pankhurst \& Collins, 2013). This support is just as important if an athlete does not make it to the level they were striving for as the family can be utilized as a mechanism to help deal with the set back, and encourage continued development at an appropriate level. Finally, such support can also be crucial to the maintenance of activity across the lifespan, making the family an important player in participation as well as performance-focused involvement (Horn \& Horn, 2007). This review aims to highlight how family may play such roles.

Significant others are integral to an athlete's social environment and, particularly for young athletes, family often provides the most important influence of all (Horn \& Horn, 2007). Although family is now portrayed within a context of fluid and changeable relationships, with the boundaries ever changing and expanding (Cowan, 1983) the most pervasive of family relations predominantly comprises of parents (whether same-sex or heterosexual) and siblings (Rittenour, Myers, \& Brann, 2007). Indeed, Brackenridge (2006) indicates that, without parental involvement, many young athletes would not be able to continue their sports participation. In similar fashion, David (2005) comments that, "when young athletes take sport very seriously and train over two hours a day, it is normal that parents become closely involved" (p. 215). In short, whether this is through transportation, financial assistance, relationships with coaches, changing family activities to fit around competition/training, emotional support or attending these competitions, parents are a key component of their child's development (LeBlanc \& Dickson: 2006). In contrast, through labelling a child as gifted (whether in sport or another domain), feelings such as rivalry, envy, 
and discontent are likely to become heightened amongst siblings of lesser talent (Cornell, 1984).

Tied closely to these considerations is Family Systems Theory (FST), which allows us to break down the family to the individual family members themselves, known as the basic elements. This allows us towards critical understanding of the environment created by the development of an elite athlete within any given unit. Moreover, all family systems have subsystems, which are likely to become even more apparent with the introduction of an elite youth athlete. This could see one or both of the parents develop an alliance with the athlete, providing support in a way that other subsystems would not. When Côté (1999) conducted a study on athletes in the specialization phase of their sport involvement he reported that, "one or both parents became more involved in their child-athlete's sport during the specialization years" (p. 407). Furthermore, this commitment to the sport can often lead to the uneven distribution of family resources (Côté \& Hay, 2002), potentially causing other elements within the system to become, or at least feel, marginalized. In short, it seems that the family has a considerable potential to help, or hinder (or maybe even both) the progress of a young talented performer.

Research in Talent Identification and Development (TID) has only recently started to consider the family as an important factor. In order to provide clarity we surmise that Talent Identification (TI) and Talent Development (TD) are inextricably linked as a two part process and that TI precedes TD. TI can be described as the process of recognizing athletes who have the potential to excel in a sport (Wiseman, Bracken, Horton \& Weir, 2014), before undertaking TD where they are provided with the most appropriate environment to accelerate learning and performance (Abbott \& Collins, 2004). In a recent review, for example, Pankhurst and Collins (2013) highlighted that TID is crucially underpinned by five constructs; Sport specialization and selection, Practice, Athlete development, Junior and adult success, 
and the stakeholders in the sport system. For the purposes of this review we will be focusing on the fifth construct; the stakeholders. In the present context, this clearly encompasses the impact which parents and, more widely, the family has on development and performance. For us as researchers in TID it raises the question; 'What can we do to help?'

Against this common acknowledgement of importance, however, there seems to be a lack of well-informed opinion. As recently as 2012, Roberts, when commenting on motivation in sport and exercise, concluded that,

... the big gap in the literature that needs to be closed is the effect of the way that parents parent! We have almost no information on the influence of the criteria of success and failure that parents impose on their children within the sport experience. (p. 24)

With this in mind, we propose a need to conduct empirical research in order to contribute to current literature, but, as importantly, to more explicitly link theory to practice. Clearly, there is a prerequisite for National Governing Bodies (NGB's) and other sporting organizations to recognize the impact which family has on elite youth sport participation, and encourage, educate and support such involvement. As Bremer (2012) explains "with all the pressure surrounding youth sport it is researchers' responsibility to provide guidance for those involved in youth sport" (p. 236).

Accordingly, this paper has three objectives; to review the main issues raised when considering the family and elite sport, to underpin these issues with the identification of the key theoretical perspectives the family elicits, and to contextualize where we are in relation to knowledge within this complex area, and where we can go from here. This is specifically tied into what we perceive as being the most relevant theory, Family Systems Theory.

Conclusions are finally offered, based around the discussion of these key issues and concepts in order to inform future direction. 


\section{Family Issues}

As suggested earlier, family issues in sport are an area that has been relatively neglected in the academic world, with many researchers calling for the need for growth within this field. With this in mind, we conducted a search for journals and book chapters, using the phrases 'family issues' and 'sport', covering the last 30 years. These topics provided the frame for the review, and were seen as face valid constructs of direct relevance to the topic of interest.

\section{What the Literature Tells Us}

Babkes and Weiss (1999) suggest that more research is needed in order to better understand the impact parents have on their child's experience, while McHale, Updegraff, and Whiteman (2012) conducted a expansive search of psychological and sociological abstracts, using the idiom 'Sibling and relation or relationship' where only a mere 741 citations were reported. This reinforces the stipulation that family is an area of TID that has been somewhat neglected. This section draws our attention to what the current literature does reveal about familial relations and their impact upon the development of one or more elite youth athletes within the family dynamic.

The key issues explored. Kay (2000) highlighted that there is currently a fundamental shift in the concept of family life, with men and women developing new expectations about their adult roles, and more importantly the contributions male and female parents make to family life. Redrawing family boundaries is becoming common practice with the definitions of social relationships continually changing, with the concept that family is a structure that fulfils a function becoming more accepted (Cheal, 2002). Such social relationships include that of the father's role within family. Work by Jeanes and Magee (2011), and Kay (2009) discuss the change in the role of the father within the family and, more specifically, within the sport domain. They conclude that, as the family landscape changes, fathers are seeing sport 
as an opportunity to bond with their child/children, and recognize the potential pressures this may put on the relationship. Notably, however, this has coincided with a shift towards dual employment. The increase in 'career couples' is placing pressure on parental relationships through both males and females being well-qualified, and pursuing 'careers' rather than 'jobs' (Gatrell, 2005). Additionally, 'work-life balance' issues, the 'long-hours culture' and the different ways that parents manage their family and employment responsibilities have also assumed greater prominence (Utting \& Pugh, 2004).

These factors have an exceptional relevance to the development of talented young athletes, as the family plays such a pivotal role in this process. Family life could be strongly influenced, and even completely driven, by the schedule and cost implications of having a gifted athlete within the family (cf. Kirk, O’Connor, Carlson, Burke, Davis, \& Glover, 1997). The presence of such an athlete impacts on the role of the parents, as they are particularly important in the context of elite youth sport, through the provision of support enabling their children to participate and progress (Horn \& Horn, 2007; Wuerth, Lee, \& Alfermann, 2004). Indeed, this has seen some parents opting to change their working day or even employment area in order to facilitate an elite athlete. Options to work shorter days, jobs that allow flexible working patterns and refusing promotion allows parents to keep themselves available in order to transport to and from, and attend their children's training sessions and competitions (Côté, 1999; Harwood \& Knight, 2009; Lauer, Gould, Roman, \& Pierce, 2010). Some families take this even further with one parent remaining in full time employment, while the other can stay at home and provide the necessary support and transport, for the athlete, at all times (Côté, 1999; Wolfenden \& Holt, 2005).

All this can have financial implications on families, which has seen parents restrict their own social lives in order to provide the necessary financial support for their young athlete (Wolfenden \& Holt, 2005; Harwood \& Knight, 2009). These demands are likely to increase 
as the child reaches higher levels of performance and gets older. A study conducted by Rowley (1992) uncovered that the costs of supporting a 12 year old swimmer more than doubled by the time they reached 14 years old, indicating how financial costs can rise disproportionately and even, perhaps, insidiously in the pursuit of higher levels of performance. Family routines may also become disrupted with the presence of an elite athlete; holidays may be re-organized and even cancelled to allow minimal interference with sporting schedules (Côté, 1999; Morgan \& Giacobbi, 2006). Family meal times often become replaced with quick and easy meals sometimes being consumed on the way to, or at, practices (Wiersma \& Fifer, 2008). These are not unproblematic changes and can lead to stress and conflict within the family unit (Barber \& Sukhi, 1998).

The impact of an elite athlete within the family does not reside merely on the role of the parents (Côté, 1999). Siblings also see a considerable, and often challenging, shift in their day to day routines and relationships. This can cause differences to arise between siblings, often arising when one sibling finds a niche, excelling at sport, causing potential bitterness and jealousy (Côté \& Hay, 2002). When the athlete did well, their siblings often felt they needed to also excel within an individual niche, which frequently lead to feelings of jealousy (cf. Fraser-Thomas, Côté, \& Deakin, 2008). Moreover, behaviors from parents can commonly see siblings split between parents in order to accommodate their activities while making sure that the elite athlete is provided with the support required, and can attend training sessions and competitions (Harwood \& Knight, 2009; Wolfenden \& Holt, 2005). Resources provided by parents commonly fall under that of time and finances and can see siblings repeatedly cast aside, often unintentionally, in order to provide the optimum environment for the gifted athlete to develop in. In addition, the expectations that significant others (parents, siblings) may have of the athlete, in relation to victory and/or replication of past success can 
have a negative effect on the performance of gifted athletes (cf. Durand-Bush \& Salmela, 2002).

This draws us to direct consideration of the influential role that parents play in their gifted athlete's development. Knight and Holt (2013) revealed in their study that parents they worked with spent a considerable amount of time researching information in relation to their child's participation in elite sport. This suggests that parents understand the importance of their role in their child's development, but don't necessarily understand the levels at which they should be committing and supporting in order to have a positive influence on their child. Progressively, parents may be able to play a more influential role in their child's sport participation if they could share more information, so that they could provide more opportunities to their child and coach, and become more aware of the various issues that arise along the parent-child relationship and its transitions (cf. Jowett \& Timson-Katchis, 2005).

This is reinforced by the widely ranging research that has been done across the field of parenting in youth sport, within a variety of contexts. For example, a perceived over involvement in a child's participation may cause the child to feel indebted to their parents, as a reaction to the level of sacrifice made, causing high levels of unreasonable pressure and expectation, leading to stress and a lack of enthusiasm (cf. Barber \& Sukhi, 1998; Leff \& Hoyle, 1995). However, athletes who become successful have acknowledged the dedication their parents have given, indicating that even higher parental involvement may be required (cf. Wuerth et al., 2004). This is consistent with Hoyle and Leff (1997), and McCarthy and Jones (2007) who summaries these perceptions of involvement by suggesting that a child enjoys their sporting involvement far more when they perceive their parents to be positively involved and satisfied with the level of participation shown by the child. White (2007) elaborated on this with the suggestion that a child's participation is strongly influenced by the motivational climate advocated by the parents, not only on the side-lines but also within the 
home/family environment. The aforementioned literature not only underpins the important role parents play in the development of a gifted athlete, but also the uncertainty of what constitutes the right level of involvement in order to positively assist in creating the optimum environment for their development. As one of the coaches interviewed in the study by Wolfenden and Holt (2005) summarized:

... the most important person is the player and everyone around them, be it coaches, parents, siblings, friends, fitness trainers, [they] have to work together to provide the optimal conditions to nurture the individuals talent. (p. 124)

The should's and should not's of family involvement. As Partridge, Brustad, and Babkes-Stellino (2008) clearly identified, parents have many opportunities during the development of their child to have both positive and negative influences. The literature provides many suggestions as to what parents should do in order to have a positive involvement. These include; helping children to understand and interpret sporting experiences, acting as role models of appropriate behaviors and attitudes, making a conscious effort to get to know teammates of their child and their parents in order to build a positive community environment, recognizing when their role changes and when they resort to providing only social support, and providing immediate feedback during competitions through verbal and non-verbal actions displayed (cf. Fredericks \& Eccles, 2004; Fry, 2010). These are all perceived as appropriate behaviors and, if conducted in the right way, can significantly contribute to an athlete's high intrinsic motivation and enjoyment of their sport, feeling competent in their ability encouraging continued participation (Ullrich-French \& Smith, 2009).

There is also similar literature informing parents about what they should not do. These include instructions on behaviors to avoid; such as overemphasizing winning and excessively criticizing their child's performance which can put pressure on the athlete, reducing sporting 
competence, and enhancing the fear of failure and competitive anxiety. They are also discouraged from providing too much feedback, as this can easily cause avoidable stress for the athlete. Indeed, too much involvement at the wrong time can have a negative impact on the development of the athlete, as a conflict of interests begins to appear between the parent and child, which can lead to lack of enthusiasm and potential dropout (cf. Dixon, Warner \& Bruening, 2008). These practical implications demonstrate a comprehensive spread of characteristics that underpin many of the theoretical perspectives linked to the family, and it is those theoretical perspectives that we now approach.

\section{Theoretical Perspectives on Family}

As is evident from the concepts of family involvement in elite sport discussed so far, the family can be seen to play a key role in the development of athletes and their progression. Our attention now turns towards the relevant theoretical underpinning that helps academics understand the role of the family, as well as aiding understanding around what the sport literature on parenting can draw from the wider theory. There are a wide range of perspectives that impact on the family, so for value and clarity we are going to highlight FST.

\section{Family Systems Theory}

Undoubtedly, the most pertinent theory in understanding the role played by the family within TID is that of FST. Accordingly, we look specifically at the evaluation, development and direction of FST.

Firstly, it is important to recognize that FST facilitates an holistic approach (Walker, 2012), taking into consideration all the family elements. These elements are the individual family members, with each element having their own set of characteristics, and independent relationships (subsystems) with each of the remaining elements (family members). This creates a structure, with each element seen to make its own unique contribution to that system, subsystem or structure, with the family being seen as a living system with all the dynamics 
implied (Walker, 2012). These dynamics are constantly fluctuating and, therefore, there will be periods within the family structure when the whole system becomes pre-occupied with one or two family members, leaving the potential for others to become marginalized (Walker, 2012). Having one member (or possibly more) as an elite youth athlete is one such circumstance under which this preoccupation may take place. This permits the potential for the marginalization of a number of different family members, whether it is a sibling or siblings, one of the parents, or a combination of those; without due care and attention the focus of the family structure can inexorably shift towards the elite athlete. This preoccupation may disrupt the family and require them, as a structure, to make alterations to their current routines, possibly causing an emotional process to take place as each member of the family will deal with this preoccupation differently depending on whether they feel marginalized or not (Walker, 2012).

The extent to which the family, as a structure, is affected by the construct of having an elite youth athlete within their system can often be dependent on the permeability of its boundaries. If these boundaries are impervious, members are likely to be insulated from the wider community; in this case the TID environment and all of its components suggesting enmeshment when one examines the independent relationships between each family member (Minuchin, 1974). The opposite to this would see the boundaries of the family structure being permeable, allowing high levels of involvement with the community (TID environment) and a level of disengagement in relation to the independent relationships (Minuchin, 1974). This process is likely to begin with a close parent-child relationship where the parent nurtures the child, before the child begins to extend their range and choice of activities, increasing their independence, but always returning to the parent for protection and re-assurance. This means that the parent encourages the child, but also has a controlling influence on the child. These are directed by the parents' own actions and attitudes, whilst they also undertake roles as 
consultants and designers of the child's immediate environment (Burton-White, 1975).

Therefore, as children grow and develop, it is advocated that parents can adapt their parenting style in order to meet the changing needs of the child, before, eventually, acknowledging the point at which their care and protection are seldom required (Jenkins, 1981). In other words, they move along the continuum from enmeshment towards permeable.

The family is a rule governed system, with the expectations that its members will behave in an organized repetitive nature creating principles of family life (Broderick, 1993). Hierarchically arranged rules are inherent within the system with the aim of remaining that way, even with any input from the environment around the family (Broderick, 1993). These rules incorporate those such as the governance of balance within the system, in the hope of bonding members coherently, with other rules regulating traffic across the boundaries of the family, in order to preserve that margin between the family and its environment. Likewise, survival in this state depends on the regulation of relationships between members in order to preserve the system, alongside regulating movement across their boundaries so that relevant information can be retrieved from the external environment, without allowing such information to fracture the family structure (Broderick, 1993). An open and on-going system can be conceptualized as a set of patterned, interactive processes. These processes have emergent qualities, and have regularities that permit rules to be inferred. These rules are commonly hierarchically structured, and contain a well-developed set of guidelines in order to maintain and regulate relationships, within the and externally of the system (Broderick, 1993).

Deposit an elite youth athlete into the system, however, and there is the potential for these guidelines to become disrupted, or re-drawn in order to create a family system that sits on a continuum somewhere between permeable or impervious, and enmeshed or disengaged. For example, hierarchically structured rules may become ineffective, as the elite athlete and their TID environment begin to dictate what is required. This may cause strain on a variety of 
independent relationships within the family, as well as the possibility of decentralizing the balance of the family system with certain relationships becoming enmeshed and others disengaged. The TID environment may also begin to encroach on the family boundaries, marginalizing certain elements.

\section{Diversity within elite sport and FST - Evolving old theory to new mores}

At this stage we feel it is important to acknowledge how factors such as gender, social class, sexuality, and race articulate within the spaces of elite sport and family systems. Cowan \& Cowan (1995) are clear with their interpretation that parental gender can affect expectations and role functioning within the family system. Reiterating earlier suggestions around the role of the father, there has been a shift in expectation in the father/athlete subsystem with the analogy of the father being a 'breadwinner', decision maker and instiller of discipline being replaced with the notions of supportiveness and approachability in order to build rapport and a relationship (Jeanes \& Magee, 2011). In contrast, the mother's role was traditionally portrayed as one to maintain a strong subsystem between themselves and their partner, and the athlete, but also between the athlete and the father, by arranging logistics and preparing food and clothing. This has since been dismissed through the increasing evidence of the emotional, psychological, and social support they offer which is essential for the development of the athlete (Chafetz \& Kotarba, 1999). As a direct consequence of such evolution, one must be careful to critically consider the literature against the social milieu and contexts in which it was framed: in short, old findings may well not hold relevance for current settings.

Such changes are also apparent within the social hierarchy. White \& McTeer (2012) argue that social class can often restrict an athlete's access to elite sport potentially causing friction within the family due to the athlete's desire to progress. Finances, location, travel accessibility, and time can all restrict opportunities to attend training/matches, purchase kit, 
and provide emotional support (Bennet, Lutz, \& Jayaram, 2012), and therefore potentially hindering TD. With youth sport becoming more professionalized barriers for participation are becoming even more apparent when social class is concerned, leaving athletes restricted and parents frustrated. We argue that this stems into the family system as it is likely to impact upon the permeability of the boundaries within the family, conceivably triggering disengagement between specific subsystems. We suggest that such implications may cause the system boundaries to become more permeable as the athlete begins to recognize the need to go outside of the family system in order to find the required support; whether this is financial support from a local authority or transport access through another athlete and their family.

Opinion around sexuality, in particularly same-sex relationships, has also developed somewhat in recent times with Lewis (2011) stipulating that society is far more accepting, and that due to the growing rates of social contact within their independent social networks, there has been a positive impact upon attitudes. We propose that this has been mirrored within the elite sport context and that, as a result, a family with same-sex parents may have a far greater permeability within their boundaries than first thought, allowing significant others (coaches, athletes, officials) to enter their subsystems in order to gain the required development. However, we must recognize this may not always be the case, and that there is still some hesitancy within society about same-sex parents raising children which may influence societal interactions (Webb \& Chonody, 2014). As far as FST is concerned this may cause athletes to develop far more enmeshed boundaries either to shut out potential negativity from significant others or reduce the exposure of their family.

As children approach adolescence they begin to spend more time interacting with external environments. When considering the concept of race this may increase their risk of experiencing discrimination from those who see themselves as the majority (Cross, 2003). 
This potential context for discrimination may see parents within the family system adopt a closed (enmeshed) system, with a reluctance to allow significant others access as a defense mechanism. In contrast the athlete may wish to move out of the boundaries in order to contact significant others who can help with their development, thus leading to a conflict within the family system, and potentially the breakdown of a number of subsystems. As Martinez (2006) depicts stress's specific to minority status may negatively impact upon parenting quality, something that supports Fuligni et al's (2013) argument that ethnic minority parent's ability to adopt a 'sensitive parenting' approach is lower than majority parents. In TD this may negatively impact upon the athlete's development as Knight, Neely, and Holt (2011) suggest that if a parent's behavior does not meet the preference of the athlete a lack of engagement may occur.

Through the application of insight this section has provided thought around the role factors such as gender, social class, sexuality, and race can play in elite youth sport. By relating these directly to FST it has allowed a more holistic viewpoint to be taken when applying the theory to practice.

\section{What Does the Theory Mean in Practice?}

The theoretical considerations outlined here support the notion that family can have a major impact on the development of an elite youth athlete, with FST being prominent in understanding the roles undertaken by the family. We will now take into consideration, how the theory we have outlined may appear in practice.

Bremer (2012) discusses the need for FST to be utilized to help inform research around families and their complex involvement in different stages of the athlete's development. FST looks at the family as a team, and recognizes the differing characteristics of each member, the individual relationships (subsystems) that can be played out at any one time, and the influence that all of these can have on the athlete. Prominent studies in the academic field have helped 
to mitigate, alleviate, and magnify the elements prominent in an elite athlete's development that are related to FST. Côté's (1999) study, for example, magnifies the way that an elite athlete's development can pre-occupy particular members within the family unit, with one subject divulging that, ... there are four of us that are involved in rowing, my [other son] is not. Yeah we have to catch ourselves and make sure that he is included. Perhaps sometimes he was overlooked. By and large, if we are together, we [try to] spread the spectrum of the conversation around. (p. 409)

From a practical perspective, both Fry (2010) and Jowett and Timson-Katchis (2005) provide insights into how families can help to create a positive environment for the athlete, and encourages high levels of interaction with coaches and teammates. This alleviates the way in which the family unit can allow its boundaries to become more permeable, encouraging the external environment to become influential to their child's development.

The above studies are some of the key work concerning the dynamic of the family unit. Each study is specific to the fifth construct of TID identified by Pankhurst et al. (2013), and focuses on the stakeholders within the sports system, with this review identifying the prominence, and importance of the family within such a construct. With the current literature available to us it is possible to come to some conclusions around the importance of the family unit in elite youth sport, and how we can support and develop this. However, as ever, there is exploration still to be done, but, how and where?

\section{Where Are We? And Where Do We Go From Here?}

Family are critical to an athlete's development (Brackenridge, 2006). With greater political support and additional funding being invested into sport, it seems logical to suggest that family too will look to invest more financially and emotionally (Brackenridge et al., 2004). Therefore, it is critical that this construct is given the attention it clearly requires. 
All of the issues surrounding the family's involvement in elite sport discussed in this paper, provide an outline of actions and behaviors by parents that may produce positive or negative reactions from the athlete. However, there is very limited direction on how parents can achieve these levels of support and behavior, and whether or not this is the same throughout the field of sport, or in fact, that different sports require different levels (Lauer et al., 2010). A result of such uncertainty could easily cause parents to unintentionally act in inappropriate ways (Wiersma \& Fifer, 2008), as they are unsure about what is perceived as correct behavior, and what types of behavior their children wish to be displayed (Harwood \& Knight, 2009). This is of great importance as athletes are highly accustomed to their parent's actions, especially before and after events, where the atmosphere remains emotionally charged (Lauer et al., 2010). On that note, Anderson, Funk, Elliott, and Smith (2003) discussed the need to gain an understanding of the preferences that young athletes place on types of parent behaviors displayed, due to their influence on development, with Knight et al. (2011) concurring that this is an area devoid of academic investigation. Alongside this need to discover athlete's preference, and the extent to the levels of parent actions, sits the third question; when should parents engage in certain types and levels of behaviors and actions (Knight at al., 2011).

There are two inputs that further research can underpin. The first is an input into the role the family unit has, with particular focus needed on parental involvement and the sibling dynamic, and how we can ease this process. For example, there is limited literature available to us around the role of siblings, with initial studies either providing little emphasis on this dynamic (cf. Côté, 1999; Côté \& Hay, 2002) or largely descriptive findings (cf. Hopwood, Farrow, MacMahon, \& Baker, 2015). The second is an input to the skill set of the athlete; building on information that can inform practice around what can be done with the athlete to help ease this process. 
When drawing attention to the initial input, it is important to continue to further uncover the relationships between the social environment, where the family unit is a fundamental component, and the internal dynamics of the coach-athlete relationship, as this relationship is critical to the athlete's achievement or potential to achieve (Jowett \& Timson-Katchis, 2005). This discovery cannot be restricted to one stage of development, however, and must take into consideration beliefs, attitudes, influences, and expectations from parents and siblings, if the whole family environment is to be explored (cf. Côté, 1999; Fredericks \& Eccles, 2004).

This work around structural, cultural and relational aspects of family in sport is imperative in order to counterbalance the perceived dominance of approaches of a sports science nature (Brackenridge, 2006). This, in turn, requires such extensive investigation that longitudinal inquiries would be idyllic, in order to exemplify different themes at different stages (Dixon, Warner, \& Bruening, 2008; Bremer, 2012). Furthermore, when considering the evidence available of practical implementation of such research, relatively few NGBs of sport have specific materials available for engaging in the development of family involvement within their sport. Additionally, even those NGBs that have not systematically monitored or evaluated their initiatives and resources making it very difficult to consider the strengths and weaknesses of such attempts (Brackenridge, 2006). This supports the notion that 'one size does not fit all', and that individual sports must be treated as that, individually. Consider the specialization ages of sports such as swimming and gymnastics in comparison to that of those such as rugby and cricket. Are parents and families going to adopt a similar approach to supporting their 8 year old gymnast as they begin to excel and become noticeable on the national stage, as they are with their 16 year old rugby player who's just broken into the academy of a top level club? These questions open up the need for investigation into the contribution of individual, parental, and familial relations within the sports context to be explored through a variety of different populations (Barnett, 2008). 
To allow these significant others to have beneficial involvement with an athlete's development, it is necessary to also conduct further research into the athletes perceptions of involvement and how they can embrace such support positively. Young athletes can provide meaningful information that can not only support current literature, but also inform future investigation (Gould, Wilson, Tuffey, \& Lochbaum, 1993); with a study by Ede, Kamphoff, Mackey, and Armentrout (2012) suggesting that young athletes aren't completely content with the level of involvement provided by their parents. Stein, Raedeke, and Glenn (1999) add to this issue by suggesting it is unclear as to why athletes view their parents' involvement as either too high or too low, and that in order to unearth such contentions we should look to examine differing athlete characteristics and parental behaviors, and how they may result in athletes perceiving the level of parental involvement, and its impact. In order to fully explore these issues it is recommended that athletes whose self-perceptions and motivational frameworks are not fully established, are observed alongside the integration of an examination of a wider span of athletes in order to capture a younger population who may be making choices in sport at an early achievement stage (Collins \& Barber, 2005).

This review has outlined the key issues and authors associated with family involvement within the TID environment, alongside what the authors perceive as being the most pertinent theoretical concepts, before finally providing potential avenues for further input. It is hoped that, through these components, we have provided a critical overview of parenting and youth sport, and highlighted that it is a complex area, but one that up until now has been broken down into components studied in isolation. This is an area that needs attention from a holistic view point, with the hope that researchers will focus future attention on this critical importance so that the parent-child relationship in elite youth sport is maximized to the full, with the family placed more centrally than at present. This will allow the development of informed and well researched interventions and resources that can only enhance this 
influential relationship and ease the burden on sporting organizations and clubs. As Bremer (2012) highlighted, "with all the pressure surrounding youth sport it is researchers' responsibility to provide guidance for those involved in youth sport" (p. 236). 
Running head: THE VALUE OF THE FAMILY IN TALENT DEVELOPMENT

\section{References}

Abbott, A., \& Collins, D. (2004). Eliminating the dichotomy between theory and practice in talent identification and development: Considering the role of psychology. Journal of Sports Sciences, 22, 395-408. doi:10.1080/02640410410001675324

Anderson, J.C., Funk, J.B., Elliott, R., \& Smith, P. (2003). Parental support and pressure and children's extracurricular activities: Relationships with amount of involvement and affective experience of participation. Applied Developmental Psychology, 24, 241-257.

Babkes, M.L., \& Weiss, M.R. (1999). Parental Influence on Children's Cognitive and Affective Responses to Competitive Soccer Participation. Paediatric Exercise Science, $11,44-62$.

Barber, H., \& Sukhi, H. (1998). 'The Influence of Parent-Coaches on Participant Motivation and Competitive Anxiety in Youth Sports Participants', Journal of Sports Behaviour 22(2): $162-80$.

Barnett, L.A. (2008). Predicting Youth Participation in Extracurricular Recreational Activities: Relationships with Individual, Parent and Family Characteristics. Journal of Park and Recreation Administration, 26, 2, 28-60. Retrieved from: http:// js.sagamorepub.com/jpra/article/viewFile/1321/1289

Bennet, P.R., Lutz, A.C., \& Jayaram, L. (2012). Beyond the schoolyard: The role of parenting logics, financial resources, and social institutions in the social class gap in structured activity participation. Sociology of Education, 85, 2, 131-157.

Brackenridge, C. (2006). The Parents' Optimum Zone: Measuring and optimising parental engagement in youth sport. Melbourne, Australia: Commonwealth International Sports Conference.

Brackenridge, C.H., Bringer, J.D., Cockburn, C., Nutt, G., Pawlaczek, Z., Pitchford, A., \& Russell, K. (2004). The Football Association's Child Protection in Football Research 
Project 2002-2006: Rationale, design and first year results. Managing Leisure - An International Journal, 9, 30-46.

Bremer, K.L. (2012). Parental Involvement, Pressure and Support in Youth Sport: A Narrative Literature Review. Journal of Family Theory and Review, 4, 235-248. doi: 10.1111/j.1756-2589.2012.00129.x

Broderick, C.B. (1993). Understanding Family Process. Basics of Family Systems Theory. London: Sage

Burton-White, B.L. (1975), 'Critical influences and the origin of competence.' Merrill Palmer Quarterly, 21, 243-266.

Chafetz, J.S., \& Kotarba, J.A. (1999). Little league mothers and the reproduction of gender. En J. Coakley \& P. Donelli (Ed.), Inside sports (pp. 41-54). London: Routledge Cheal, D. (2002). Sociology of Family Life. Basingstoke: Palgrave Macmillan.

Collins, K., \& Barber, H. (2005). Female Athletes' Perceptions of Parental Influence. Journal of Sport Behaviour, 28, 4, 295-314. doi: 01627341, 20051201

Cornell, D.G. (1984). Families of gifted children. Am Arbor, MI: UMI Research Press.

Côté, J. (1999). The influence of the family in the development of talent in sport. Sport Psychologist, 13: 395-417.

Côté, J., \& Hay, J. (2002). Family influence on youth sport performance and participation. In J.M. Silva \& D. Stevens (Eds.) Psychological Foundations of Sport (2 ${ }^{\text {nd }}$ Ed.) (pp. 503519). Boston: Allyn and Bacon.

Cowan, C.P., \& Cowan, P.A. (1995). Interventions to ease the transition to parenthood: why they are needed and what they can do. Family Relations, 44, 412-423.

Cowan, R.S. (1983). More Work for Mother: The Ironies of Household Technology from the Open Hearth to the Microwave. New York: Basic Books. 
Cross, W. E, Jr. (2003). Tracing the historical origins of youth delinquency and violence: Myths and realities about Black culture. Journal of Social Issues, 59 (1), 67-82.

David, P. (2005). Human Rights in Youth Sport. London: Routledge.

Dixon, M. A., Warner, S. M., \& Bruening, J. E. (2008). More than just letting them play: The enduring impact of parental socialization on female sport involvement. Sociology of Sport Journal, 25, 538-559. doi: 10.1080/13573322.2013.774273

Durand-Bush, N., \& Salmela, J. H. (2002). The development and maintenance of expert athletic performance: Perceptions of World and Olympic champions. Journal of Applied Sport Psychology, 14, 154-171. doi: 10.1080/10413200290103473

Ede, S., Kamphoff, C.S., Mackey, T., \& Armentrout, S.M. (2012). Youth hockey athletes; perceptions of parental involvement: They want more. Journal of Sport Behaviour, 35, $1,3-18$.

Fraser-Thomas, J., Côté, J., \& Deakin, J. (2008). Understanding dropout and prolonged engagement in adolescent competitive sport. Psychology of Sport and Exercise, 9, 5, 645-662. doi: 10.1016/j.psychsport.2007.08.003

Fredricks, J.A., \& Eccles, J.S. (2004). Parental influence on youth involvement in sports. In M.R Weiss (Ed.) Developmental sport \& exercise psychology: A lifespan perspective. (pp. 145-164). Morgantown, NV: Fitness Information Technology.

Fry, M. (2010). Creating a Positive Climate for Young Athletes from Day 1. Journal of Sport Psychology in Action. 1, 33-41. doi: 10.1080/21520704.2010.518224

Fuligni, A. S., Brady-Smith, C., Tamis-LeMonda, C. S., Bradley, R. H., Chazan-Cohen, R., Boyce, L., \& Brooks-Gunn, J. (2013). Patterns of supportive mothering with 1-, 2-, and 3-year-olds by ethnicity in early head start. Parenting: Science and Practice, 13, 44 57.doi:10.1080/15295192.2013.732434 
Gatrell, C. (2005). Hard Labour: The Sociology of Parenthood. New York: McGraw-Hill Education.

Gould, D., Wilson, C. J., Tuffey, S., \& Lochbaum, M. (1993). Stress and the young athlete: The child's perspective. Paediatric Exercise Science, 5, 286-297.

Harwood, C., \& Knight, C. (2009). Understanding parental stressors: An investigation of British tennis-parents. Journal of Sports Sciences, 27(4), 339-351.

Hopwood, M.J., Farrow, D., MacMahon, C., \& Baker, J. (2015). Sibling dynamics and sport expertise. Scandanavian Journal of Medicine and Science in Sports. doi: 10.1111/sms.12387.

Horn, T.S., \& Horn, J.L. (2007). Family influences on children's sport and physical activity participation, behaviour, and psychosocial responses. In G. Tenenbaum \& R.C. Eklund (Eds.), Handbook of sport psychology (pp. 685-711). New York: Wiley.

Hoyle, R., \& Leff, S. (1997). The role of parental involvement in youth sport participation and performance. Adolescence 32, 125, 233-243.

Jeanes, R., \& Magee, J. (2011). Come on my son! Examining fathers, masculinity and 'fathering through football.' Annals of Leisure Research, 14,2, 273-288.

Jenkins, H. (1981). “Can I (let you let me) leave?” Therapy with the adolescent and his family. Journal of Family Therapy, 3,2, 113-138.

Jowett, S., \& Timson-Katchis, M. (2005). Social Networks in Sport: Parental Influence on the Coach-Athlete Relationship. The Sport Psychologist, 19, 267-287.

Kay, T. (2000). Sporting Excellence: A Family Affair? European Physical Education Review, 6, 2, 151-169. doi: 10.1177/1356336X010073002

Kay, T. (2009). The landscape of fathering. In T. Kay (Ed.), Fathering Through Sport and Leisure. (pp.1-22). London: Routledge. 
Kirk, D., O’Connor, A., Carlson, T., Burke, P., Davis, K., \& Glover, S. (1997). Time commitments in junior sport: Social consequences for participants and their families. In the European Journal of Physical Education 1997(2), 51-73. doi: $10.1080 / 1740898970020105$

Knight, C.J., \& Holt, N.L. (2013). Factors that influence parent's experiences at junior tennis tournaments and suggestions for improvement. Sport, Exercise and Performance Psychology, 2, 3, 173-189.

Knight, C.J., Neely, K.C., \& Holt, N.L. (2011) Parental Behaviours in Team Sports: How do Female Athletes Want Parents to Behave? Journal of Applied Sport Psychology, 23, 7692. doi: $10.1080 / 10413200.2010 .525589$

Lauer, L., Gould, D., Roman, N., \& Pierce, M. (2010). How parents influence junior tennis player's development: Qualitative narratives. Journal of Clinical Sports Psychology, 4, 69-92.

LeBlanc, J., \& Dickson, L. (2006). Straight talk about children and sport. Athens: Lector EPE.

Leff, S., \& Hoyle, R. (1995). Young athlete's perceptions of parental support and pressure. Journal of Youth and Adolescence, 24, 187-203.

Lewis, G. B. (2011). The friends and family plan: Contact with gays and support for gay rights.

Policy Studies Journal, 39 (2), 217-238. doi: 10.1111/j.1541-0072.2011.00405.x

Martinez, C. R. (2006). Effects of differential family acculturation on Latino adolescent substance use. Family Relations: An Interdisciplinary Journal of Applied Family Studies, 55, 306-317. doi:10.1111/j.1741-3729.2006.00404.x

McCarthy, P.J., \& Jones, M.V. (2007). A qualitative study of sport enjoyment in the sampling years. The Sport Psychologist, 21, 400-416. Retrieved from 
http://journals.humankinetics.com/tsp-back-

issues/tspvolume21issue4december/aqualitativestudyofsportenjoymentinthesamplingyea

$\underline{\mathrm{rs}}$

McHale, S.M., Updegraff, K.A., \& Whiteman, S.D. (2012). Sibling Relationships and Influences in Childhood and Adolescence. Journal of Marriage and Family, 74, 5, $913-$ 930. doi: 10.1111/j.1741-3737.2012.01011.x

Minuchin, S. (1974). Families and family therapy. Cambridge, MA: Harvard University Press. Morgan, T.K., \& Giacobbi, P.R. (2006). Toward two grounded theories of talent development and social support process of highly successful collegiate athletes. The Sport Psychologist, 20, 295-313.

Pankhurst, A., \& Collins, D. (2013). Talent Identification and Development: The need for coherence between research, systems, and process. Quest, 65, 83-97.

Pankhurst, A., Collins, D., \& MacNamara, A. (2013). Talent development: Linking the stakeholders to the process. Journal of Sports Sciences, 31, 4, 370-380.

Partridge, J. A., Brustad, R. J., \& Babkes Stellino, M. (2008). Social influence in sport. In T. S. Horn (Ed.), Advances in sport psychology, Third Edition (pp. 269-292). Champaign, IL: Human Kinetics.

Rittenour, C.E., Myers, S.A., \& Brann, M. (2007). Commitment and Emotional closeness in the sibling relationship. Southern Communication Journal, 72, 169-183. doi: $10.1080 / 10417940701316682$

Roberts, G.C. (2012). Motivation in Sport and Exercise From an Achievement Goal Theory Perspective. After 30 years, where are we? In G.C. Roberts \& D.C. Treasure (Eds.) Advances in Motivation in Sport and Exercise. (pp. 5-58). Champaigne, IL: Human Kinetics. 
Rowley, S. (1992). TOYA (Training of Young Athletes Study): Identification of Talent. London: The Sports Council.

Stein, G.L., Raedeke, T.D., \& Glenn, S.D. (1999). Children's perceptions of parent sport involvement: It's not how much, but to what degree that's important. Journal of Sport Behaviour, 22, 1-8.

Ullrich-French, S., \& Smith, A. L. (2006). Social and motivational predictors of continued youth sport participation. Psychology of Sport and Exercise, 10, 87-95. doi: 10.1016/j.psychsport.2008.06.007

Utting, D., \& Pugh, G. (2004). The social context of parenting. In M. Hoghughi \& N. Long (Eds.). Handbook of Parenting: Theory and Research for Practice. (pp. 19-37). London: Sage.

Walker, S. (2012). Effective Social Work with Children, Young People \& Families. Putting Systems Theory into Practice. London: Sage.

Webb, S.N., \& Chonody, J. (2013). Heterosexual attitudes towards same-sex marriage: The influence of attitudes toward same-sex parenting. Journal of GLBT Family Studies, 10, 4, 404-421. doi: 10.1080/1550428X.2013.832644

White, P., \& McTeer, W. (2012). Socioeconomic Status and Sport Participation of Different Development Stages During Childhood and youth: Multivariate Analyses Using Canadian National Survey Data. Sociology of Sport Journal, 29, 186-209.

White, S.A. (2007). Parent-Created Motivational Climate. In S. Jowett \& D. Lavallee (Eds.) Social Psychology in Sport (pp. 132-143). Champaign, IL: Human Kinetics.

Wiersma, L.D., \& Fifer, A.M. (2008). 'The schedule has been tough but we think it's worth it.' The joys, challenges, and recommendations of youth sport parents. Journal of Leisure Research, 40, 505-530. 
Wiseman, A.C., Bracken, N., Horton, S., \& Weir, P.L. (2014). The Difficulty of Talent Identification: Inconsistency Amongst Coaches Through Skill-Based Assessment. International Journal of Sports Science and Coaching, 9, 3, 447-455.

Wolfenden, L.E., \& Holt, N.L. (2005). Talent development in elite junior tennis: Perceptions of players, parents, and coaches. Journal of Applied Sport Psychology, 17, 108-126. doi: $10.1037 / \mathrm{a} 0031203$

Wuerth, S., Lee M.J., \& Alfermann, D. (2004). Parental involvement and athlete's career in youth sport. Psychology of Sport \& Exercise. 5, 21-33. doi: 10.1016/S14690292(02)00047-X 